Zur Trennung zweier Klassen von menschlichen Serumproteinen wird die Gelfiltration herangezo. gen, bei der vernetzte Dextranpolysaccharide Substanzen mit verschiedenem Molekulargewicht tren. nen. Man eluiert mit Natriumphosphatpuffer pr 8 . Während das eine der Serumproteine (Euglobulin) in Lösungen, niederer Tonenstärke unlöslich ist und bis zu einer Front zurückgehalten wird, die das Lösungsmittel zur Beladung der Säule mit dem Serum enthält, ist das Pseudoglobulin in einom Medium niederer Ionenstärke löslich und wird von dem Puffer eluiert. Zur Identifizierung werden die einzelnen Fraktionen spektralphotometrisch untersucht.

$$
\text { J. Sunkel (Frankfurt a. M.) }
$$

Kung, J. T., J. E. Whitney u. J. C. Cavagnol (Res. Center, General Foods Corp., Tarrytown, N. Y., USA). Gaschromatographische Analyse wä8riger Iösungen. (Anal. Chem. 33, 1505-1507, 1961.)

Bei der gaschromatographischen Trennung wäBriger Lösungen treten besonders bei hohen Wassergehalten Störungen durch die große Was. serspitze auf. Außerdem kann das Wasser mit der stationären Phase reagieren und dadurch die Lebensdauer der Säule verkürzen. Die Autoren schalten daher vor die eigentliche Trennsäule eine heizbare Säule mit $\mathrm{CaC}_{2}$, die das Wasser in Acetylen umwandelt. Die Acetylenspitze erscheint schon nach kurzer Zeit und stöxt die späteren Komponenten nicht mehr. Mit dieser Apparatur kann man bis zu $90 \%$ wäßrige Lösungen analysieren und benötigt dazu eine $1,8 \times 30 \mathrm{~cm}$ große $\mathrm{CaC}_{2}$-Säule. Es wird die Trennung wäßriger Lösungen von Alkohol, Ester und Aldehyd beschrieben.

J. Sunkel (Frankfurt a. M.)

Nakagawa, T. H., Inoue u. K. Kuriyama (Res Labor., Shionogi u. Co. Ltd., Amagasaki, Japan). Nachweis von Verunreinigungen in nichtionisehen Waschmitteln durch die Gaschromatographie. (Anal. Chem. 83, 1524-1526, 1961.)

Die hauptsächlichen Verunreinigungen die bei nichtionischen Waschmitteln auftreten, sind Polyäthylenglykole, langkettige Alkohole und Fettsäuren. Während für die Fettsäuren und die hochmolekularen Polyäthylenglykole Analysemethoden vorhanden sind, macht der Nachweis von niedermolekularen Polyäthylenglykolen und langkettigen Alkoholen einige Schwierigkeiten. Die Autoren beschreiben eine quantitative gaschromatographische Bestimmung dieser Komponenten bei $200^{\circ}$ mit einer Ziegelmehlsäule, die Silikonöl als stationäre Phase enthält. Für die Polyäthylenglykole sowie ihre Mono- und Dimethyläther findet man einen linearen Zusammenhang zwischen dem Logarithmus des Retentionsvolumens und der Anzahl der Oxyäthyleneinheiten.

$$
\text { J. Sunkel (Frankfurt a. M.) }
$$

Stoffer, R.L. u. W.E.Smith (Res. and Developm. Dept., American Oil Co. Whiting, Ind. USA; Res. Dept., Ameo Chemicals Corp., Whiting, Ind., USA). Die Zusammensetzung markierter Äthylen/Propylen-Copolymere. (Anal. Chem. 23, 1112-1113, 1961.)

Es wird eine Methode zur Bestimmung von mit ${ }^{14} \mathrm{C}$ markierten Äthylen/Propylen-Copolymeren angegeben. Das Copolymer wird bei etwa $120^{\circ}$ in Xylol, das einen Szintillator enthält, gelöst. Beim Abkühlen bildet sich ein Gel, das mit dem Szintillator eine Mischung bildet. Die Zählausbeute beträgt $70 \%$, und man benötigt etwa $0,5 \mathrm{~g}$ Copolymer. Die Methode ist auch für andere Copoly. meren anwendbar. J. Sunkel (Frankfurt a. M.)

\section{Kunststoffe und Kautschuk}

\section{a) Polyplaste}

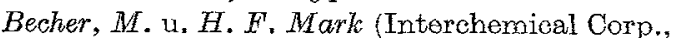
Central Res. Labors. New York; Polymer Res. Inst., Polytechnic Inst., Brooklyn, N. Y., USA). Polymere als elektrische Leiter und Halbleiter. (Angew. Chem. 73, 641-646, 1961.)

Elektrisch leitende Kunststoffe erhält man, indem man in das Produkt bewegliche Ionen einbaut, wie z. B. durch Ersatz der Protonen in Polyäthylen mit Carboxyl-Seitengruppe durch Na-Ionen. Eine weitere Möglichkeit besteht in der Einführung von Elektronen, was am Beispiel der Polyvinyleno, der Chelate und einiger Heteroverbindungen gezeigt wird. So besitzen Polyvinylene mit einer langen Reihe konjugierter Doppelbindungen Halbleitereigenschaften. Man erhält sie durch Pyrolyse, Polykondensation und Photolyse. Sowohl die magnetische Susceptibilität wie auch die Intensitäten der Elektronenspin-Resonanz sprechen für das Vorhandensein unpaariger Elektronen. Weiterhin zeigen die Phthalocyanine und die Chelatkomplexe von Tetracyanäthylen Halbleitereigenschaften. Von den Polymeren mit Heteroatom erwiesen sich die Kondensationsprodukte von Phthalsäureanhydrid, Hydrochinon und p-Phenylendiamin sowie aromatische Verbindungen mit Chinon- und Aminogruppe in der Konjugationskette als Halbleiter. J. Sunkel (Frankfurt a. M.)

\section{Gerberei}

Stather, F., M. Gierth u. A. Meissner (Freiberg/ Sa.). Neue Giiterichtlinien für Leder. (Gesamm. Abh. Deutsch. Lederinst. Freiberg 16, 104-136, 1960.)

In 5 in sich wieder in 4-7 Gruppen unterteilte Lederstandards und 23 Tabellen der technischen Forderungen werden die Richtlinien mitgeteilt und ergänzt durch je eine Übersicht der Prüfmethoden und der Arbeitsvorschriften.

$$
\text { H.H. Pfeiffer (Bremen) }
$$

\section{Keramik, Ton, Zement, Glas, anorganische Farbstoffe}

Straka, R. C. jr. (Carborundum Comp., Niagara Falls, N. Y., USA). Produktionsformen von keramischen Aluminiumsilicat-Fasern. (Amer. Ceram. Soc. Bull. 40, 493-495, 1961.)

Durch während des Gießprozesses erfolgtes Abschrecken im Luft- oder Dampfstrom von im elektrischen Lichtbogenofen geschmolzenen Tonerde-Mullit-Míschungen kann man seit 1942 an Stelle von massiven oder. Hohlkügelchen auch hoch feuerfeste Fasern mit Durchmesser von weniger als $0,1 \mu$ herstellen. Als optimale Mischung wird angegeben: 50 Teile weißes Al-Erz, 50 T. Flint, $\mathrm{l}_{1} \mathrm{~T}$. Boraxglas, Gießtemperatur $3400{ }^{\circ} \mathrm{F}$. Beschrieben werden Zugfestigkeit, Schmelzpunkt, maximale Verwendungstemperatur und spezifisches Gewicht yon 4 Faserarten mit Abmessungen zwischen 80 und $0,1 \mu$ Dicke and $1 / 4$ bis $10 \mathrm{in}$. Länge in Form von Papier, Gewebe, Verputzmaterial, Ưberzügen, Platten, Kordeln usw. 